\title{
ACCURACY OF SIRI AND BROZEK EQUATIONS IN THE PERCENT BODY FAT ESTIMATION IN OLDER ADULTS
}

\author{
R.S. GUERRA1', T.F. AMARAL 12,2, E. MARQUES ${ }^{3}$, J. MOTA³ ${ }^{3}$ M.T. RESTIVO ${ }^{1}$ \\ 1. UISPA-IDMEC, Faculty of Engineering, University of Porto, Porto Portugal; 2. Faculty of Nutrition and Food Sciences, University of Porto, Porto, Portugal; 3. Research Centre in \\ Physical Activity, Health and Leisure, Faculty of Sport Sciences, University of Porto, Portugal; 4. Corresponding Author: Teresa F. Amaral, Faculty of Nutrition and Food Sciences, \\ University of Porto, Rua Dr. Roberto Frias, 4200-465 Porto, Portugal. Phone: 3512250743 20, Fax: 3512250743 29, e-mail: amaral.tf@ gmail.com
}

\begin{abstract}
Objective: To identify which equation, Siri or Brozek, based on the two compartment model, provides a more accurate conversion of body density (BD) in percent body fat $(\% \mathrm{BF})$ in a group of older adults. Study design: Cross-sectional study. Setting: Research Centre in Physical Activity, Health and Leisure, Faculty of Sport, University of Porto. Participants: 60 older adults, aged 60-92 years. Measurements: Skinfold thickness was used to estimate BD through Visser et al. prediction equation. The conversion of BD to \%BF was done with Siri (\%BF-Siri) and Brozek (\%BF-Brozek) formulas and these determined values were both compared to DualEnergy X-ray Absorptiometry (\%BF-DXA) evaluations. Results: A strong correlation between the \%BF-DXA value and \%BF-Siri $(\mathrm{r}=0.91, \mathrm{p}<0.001)$ and \%BF-Brozek $(\mathrm{r}=0.91, \mathrm{p}<0.001)$ was found, although \%BF-Siri and $\%$ BF-Brozek overestimated \%BF-DXA $(\mathrm{p}<0.001)$. The comparison of the \%BF-Siri and \%BF-Brozek mean values also revealed significant differences $(\mathrm{p}<0.001)$. The $\%$ BF-Brozek reflects a better agreement than the $\% \mathrm{BF}-$ Siri with \%BF-DXA with respectively a mean difference of $-4.0 \% \mathrm{BF}$ (limits of agreement $=-10.9$ to $2.9 \%$ ) and $-5.7 \% \mathrm{BF}$ (-12.6 to 1.2). The Bland and Altman plots confirmed that \%BF-Brozek reflects a better agreement with \%BF-DXA. Conclusion: The results of the present study show that the use of Brozek equation may correspond to a more accurate alternative than Siri equation for the conversion of BD in \% BF in older adults.
\end{abstract}

Key words: Older adults, percent body fat, Siri, Brozek, two compartment model.

\section{Introduction}

Accurate body fat (BF) evaluation is an important objective of nutritional assessment of older people (1). However, commonly used methods for assessing body composition such as underwater weighing and air displacement are not suitable for daily practice and may be not appropriate for older people who are not able to cope with these procedures $(1,2)$.

The skinfold thickness (ST) measurement in distinct and pre defined body locations allows direct measurement of the subcutaneous adipose tissue thickness (1). The ST provides a good approximation for total BF, allowing the prompt identification of abnormal situations and is useful to evaluate the dynamic changes of an individual's local or total fat (3). Compared to other procedures for estimating body composition, the ST measurement is a non invasive, very convenient, easy, inexpensive and a highly informative technique to be used in older people (4).

Skinfold thickness measurement can be directly converted in percent $\mathrm{BF}(\% \mathrm{BF})$ or may require body density (BD) calculation using regression equations and further conversion in $\% \mathrm{BF}$ through distinct prediction formulas. Equations for directly converting skinfold measurement to $\% \mathrm{BF}$ are only available for younger olders (60 years old) (5) or nonCaucasian olders $(6,7)$, as opposed to adults (8-11). Therefore, the \%BF estimation based on ST measurement, as in other methods like underwater weighting, requires the BD calculation and then its conversion in $\% \mathrm{BF}$, through equations. Siri $(\% \mathrm{BF}$ $\left.=\left[4.950 / \mathrm{BD}\left(\mathrm{kg} / \mathrm{m}^{3}\right)-4.500\right] \times 100\right)(12)$ or Brozek $(\% \mathrm{BF}=$ [4.570/ BD $\left.\left.\left(\mathrm{kg} / \mathrm{m}^{3}\right)-4.142\right] \times 100\right)$ (13) formulas are the most commonly used for this purpose (14).
It is also known that the selection of the most appropriate equation should consider its validity within the population under study (15). The adequacy of Siri two compartment model for converting $\mathrm{BD}$ to $\% \mathrm{BF}$ in older people has already been discussed $(16,17)$. Previous studies have suggested that statements of Siri were appropriate for healthy old men but not for older women (16) and that Siri equation, depending on age, overestimates $\%$ BF by $2-3 \%$ in older individuals (17). The Brozek equation, originally developed for non-athletic young adult males, has subsequently been applied to different populations, including older adults (3). Although the study of the accuracy of these two equations has already been done in adults $(18,19)$, in older people it remains to be seen which equation provides a more accurate transformation of $\mathrm{BD}$ in $\% \mathrm{BF}$.

Therefore, the purpose of the present study is to identify which equation, Siri or Brozek, provides a more valid transformation of $\mathrm{BD}$ in \%BF within older people. As DualEnergy X-ray Absorptiometry (DXA) is a well established reference method for the assessment of older individuals body composition $(20,22)$, it was chosen as a criterion method.

\section{Materials and Methods}

\section{Subjects and design}

This was a university-based, cross-sectional study carried out on a convenience sample of older individuals, living in Porto, Portugal. The sample included 35 women aged 60-92 years, and 25 men aged 61-82 years, engaged in an exercise program at the Physical Activity, Health and Leisure Research 


\section{ACCURACY OF SIRI AND BROZEK EQUATIONS IN THE PERCENT BODY FAT ESTIMATION IN OLDER ADULTS}

Centre, in the Faculty of Sports at University of Porto. The study was designed in accordance to the Helsinki Declaration (23) and the individuals were advised about the study aims, methodology to be used and also their free right of refusal. All participants gave their informed consent.

\section{Body composition measurement}

Percent of BF was evaluated by a trained technician, in DXA equipment (Hologic QDR-4500®) (\%BF-DXA). Simultaneously, ST measurement was carried out with a Harpenden calliper (precision of $0.2 \mathrm{~mm}$ ) using triceps, biceps, subscapular and iliac crest sites, along the right body side and measurement were repeated three consecutive times, according to the International Standards for Anthropometric Assessment recommendations (24). Both the calliper and the DXA were previously calibrated.

Body density was calculated from ST using Visser et al. equation (2): $\mathrm{BD}\left(\mathrm{kg} / \mathrm{m}^{3}\right)=1.0668+0.0212 \mathrm{x}$ sex -0.0356 $\log _{10}$ (triceps + biceps + subscapular + iliac crest) (sex, 0 for women, 1 for men, skinfolds thickness in $\mathrm{mm}$ ), and converted to \%BF with both Siri (\%BF-Siri) and Brozek (\%BF-Brozek) equations. As prediction formulas for directly converting skinfold measurement to \% BF are only available for younger olders (5) or non-Caucasian olders $(6,7)$, Visser et al. equation was used as it was developed in a population of older individuals $(n=204$, aged 60-87 years old) to transform ST measurement in BD. Internal cross validation and external validation revealed that this was a valid equation for estimation of BD in older subjects (2).

Height and body mass were collected according to standard procedures (24). Height (m) was measured with the individuals barefoot, using a stadiometer (Seca 708) of $0.01 \mathrm{~m}$ precision. Body mass $(\mathrm{kg})$ was measured by a scale incorporated in the DXA equipment with precision of $0.1 \mathrm{~kg}$ with individuals barefoot and wearing light clothes. BMI was calculated using the standard formula: [mass $(\mathrm{kg}) /$ height $^{2}(\mathrm{~m})$ ].

\section{Other data}

Information regarding gender, date of birth, academic qualifications and exercise practice was collected for the overall description of the sample.

\section{Data analysis}

Estimation of $\% \mathrm{BF}$ from ST converted to $\% \mathrm{BF}-$ Siri and $\% \mathrm{BF}-\mathrm{Brozek}$, was compared to \%BF-DXA. According to gender and age, \%BF-DXA mean values were compared to reference values from Coin et al. (25).

In order to determine if both age and BMI have impact on differences between the standard and the equations used, the discrepancy between \%BF-DXA and \%BF-Siri and between $\%$ BF-DXA and \%BF-Brozek was stratified by age and BMI classes. Subjects were grouped in two age classes: $<70$ and $\geq 70$ years old and three BMI classes, according to the current World Health Organization standards (26): normal weight (18.5-24.9 $\left.\mathrm{kg} / \mathrm{m}^{2}\right)$, pre-obese $\left(25.0-29.9 \mathrm{~kg} / \mathrm{m}^{2}\right)$ and obese group $\left(30.0-34.9 \mathrm{~kg} / \mathrm{m}^{2}\right)$. Differences of \%BF value between DXA and both \%BF-Siri and \%BF-Brozek estimations were also stratified for values less and $\geq 30 \%$ and gender. Because this stratification resulted in very small numbers in some strata, the $<30 \% \mathrm{BF}$ group was composed of 1 woman and the $\geq 30 \% \mathrm{BF}$ of 3 men, differences were not analysed.

Frequencies were calculated to describe categorical variables. Means and standard deviation (SD) were computed for the quantitative and continuum variables. The Normal distribution of the variables was tested using the Kolmogorov Smirnov test. Association between \%BF-DXA and \%BF-Siri and between \%BF-DXA and \%BF-Brozek was evaluated by Spearman's correlation coefficients (r). Differences between $\%$ BF-DXA and both \%BF-Siri and \%BF-Brozek were evaluated using Wilcoxon Signed Ranks test. Differences between age and BMI groups were evaluated by Independent Samples $t$ test or One Way Anova test.

The visual agreement between \%BF-DXA and both \%BFSiri and \%BF-Brozek was evaluated assessing the Bland and Altman plots (27). Limits of agreement were calculated as mean of the difference - 2SD and mean of the difference + 2SD.

Results were considered significant when $p<0.05$. All statistical analyses were carried out using the Software Package for Social Sciences (SPSS) for Windows, version 14.0 (SPPS Inc. Chicago, Il, USA).

\section{Results}

The baseline characteristics of our sample are summarized in Table 1 . The educational level is low as only $40 \%$ participants completed $\geq 5$ school years. The majority of the sample participated in a physical activity programme 2-3 days/week ( $77.1 \%$ of women and $72.0 \%$ of men) and the others $\geq 4$ days/week.

Table 1

Subject characteristics and body fat estimation

\begin{tabular}{lcccc}
\hline & \multicolumn{2}{c}{ Women $(\mathbf{n}=\mathbf{3 5})$} & \multicolumn{2}{c}{ Men $(\mathbf{n = 2 5})$} \\
& mean & SD & mean & SD \\
\hline Age (years) & 73.0 & 6.0 & 70.7 & 4.9 \\
Height (m) & 1.53 & 0.06 & 1.68 & 0.05 \\
Body mass (kg) & 61.1 & 7.2 & 76.7 & 9.1 \\
BMI (kg/m $\left.{ }^{2}\right)$ & 26.2 & 3.4 & 27.1 & 2.5 \\
BF-DXA (\%) & 37.5 & 4.8 & 25.9 & 4.1 \\
BF-Siri1,3 (\%) & 43.8 & 2.0 & 30.7 & 1.3 \\
BF-Brozek $2,3,4(\%)$ & 41.7 & 1.8 & 29.6 & 1.2 \\
\hline
\end{tabular}

SD: standard deviation, BMI: body mass index; BF: body fat; DXA: Dual-Energy X-ray Absorptiometry. 1. Skinfolds measurement converted in \%BF using Visser et al. (2) and Siri (12) equations (\%BF-Siri). 2. Skinfolds measurement converted in \%BF using Visser et al. (2) and Brozek (13) equations (\%BF-Brozek). 3. p $<0.001$ Wilcoxon Signed Ranks Test for \%BF-DXA versus \%BF-Siri and by \%BF-DXA versus \%BF Brozek; 4. p <0.001 Wilcoxon Signed Ranks Test for \%BF-Siri versus \%BF-Brozek. 
Considering \%BF-DXA, 19 women (54.3\%) and 18 men $(72.0 \%)$, were within $\% \mathrm{BF}$ age and gender specific reference values (25). A higher proportion was above $(28.6 \%$ women and $16.0 \%$ men) than below (17.1\% women and $12.0 \%$ men) these $\% \mathrm{BF}$ reference values.

A strong correlation between the \%BF-DXA value and $\%$ BF-Siri $(r=0.91, p<0.001)$ and \%BF-Brozek $(r=0.91$, $\mathrm{p}<0.001$ ) was found. Despite these good correlations, \%BF-Siri and \%BF-Brozek overestimated \%BF-DXA for both men and women $(\mathrm{p}<0.001)($ Table 1$)$. The results have also shown significant disparities between \%BF-Siri and \%BF-Brozek $(p<0.001)($ Table 1) despite its excellent agreement $(r=1.0$, $\mathrm{p}<0.001)$.

The \%BF-Brozek reflects a better agreement with \%BFDXA than the \%BF-Siri, with respectively a mean difference of $-4.0 \% \mathrm{BF}$ (limits of agreement $=-10.9$ to $2.9 \%$ ) against $5.7 \% \mathrm{BF}$ ( -12.6 to 1.2$)$. Considering the mean difference between these differences [(\%BF-DXA - \%BF-Siri) minus (\%BF-DXA - \%BF-Brozek)], the \%BF-Brozek was $1.7 \%$ (SD: $0.5 \%$ ), closer to the \%BF-DXA evaluation for the overall sample. When stratified by gender, we found this mean difference was equal to $2.1 \%$ (SD: $0.2 \%$ ) for the women and to $1.1 \%$ (SD: $0.1 \%$ ) for the men.

After stratifying by age and BMI (Table 2), differences between \%BF-DXA and from prediction equations remain higher for \%BF-Siri than for \%BF-Brozek. In regards to the age groups, these mean differences were slightly higher in both men and women aged 70 and older than in those younger than 70 , but they did not reach statistical significance. With respect to BMI, significant differences were found between the normal, pre-obese and obese women $(\mathrm{p}<0.001$ for $\%$ BF-Brozek and $\mathrm{p}=0.001$ for $\% \mathrm{BF}$-Siri versus $\% \mathrm{BF}-\mathrm{DXA}$ ) and differences were superior for men and women with a BMI between 18.5 and $24.9 \mathrm{~kg} / \mathrm{m}^{2}$ than for pre-obese or obese. As these results are based on small numbers, their interpretation deserves further caution.
Figure 1

Bland and Altman plot (27) for the difference against average of body fat (\%) by DXA and by skinfolds, Visser et al. (2) and Siri (12) equations

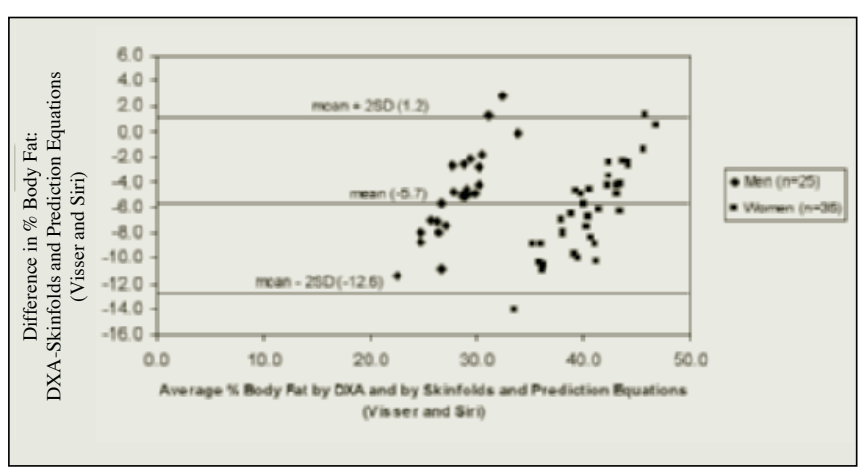

Figure 2

Bland and Altman plot (27) for the difference against average of body fat (\%) by DXA and by skinfolds, Visser et al. (2) and Brozek (13) equations

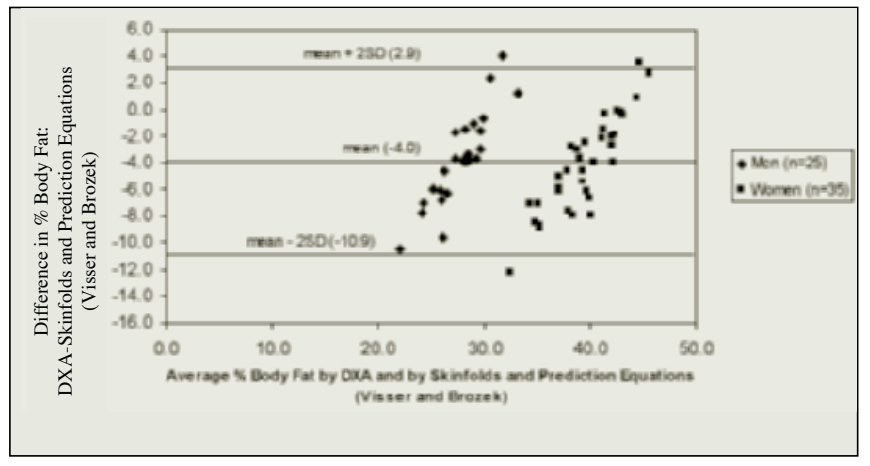

The Bland and Altman plots from \%BF-DXA against the results from \%BF-Siri and from \%BF-Brozek are presented in Figures 1 and 2, respectively. Although none of the pair of equations reflects an excellent visual agreement with DXA (27)

Table 2

Body fat differences from skinfolds and prediction equations versus Dual-Energy X-ray Absorptiometry

\begin{tabular}{|c|c|c|c|c|c|c|c|c|c|c|}
\hline & \multicolumn{6}{|c|}{ Women } & \multicolumn{4}{|c|}{ Men } \\
\hline & \multirow[t]{2}{*}{$\mathbf{n}$} & \multicolumn{2}{|c|}{$\%$ BF-Siri ${ }^{1}$} & \multicolumn{2}{|c|}{$\%$ BF-Brozek $^{2}$} & \multirow[t]{2}{*}{$\mathbf{n}$} & \multicolumn{2}{|c|}{$\%$ BF-Siri ${ }^{1}$} & \multicolumn{2}{|c|}{$\%$ BF-Brozek ${ }^{2}$} \\
\hline & & mean & SD & mean & SD & & mean & SD & mean & SD \\
\hline BF Difference ${ }^{3}(\%)$ & 35 & -6.3 & 3.5 & -4.2 & 3.5 & 25 & -4.8 & 3.4 & -3.7 & 3.5 \\
\hline \multicolumn{11}{|l|}{$\mathrm{Age}^{4}$ (years) } \\
\hline$<70$ & 8 & -6.1 & 3.5 & -4.0 & 3.4 & 10 & -4.3 & 3.7 & -3.2 & 3.8 \\
\hline$\geq 70$ & 27 & -6.3 & 3.5 & -4.2 & 3.6 & 15 & -5.2 & 2.3 & -4.1 & 3.3 \\
\hline \multicolumn{11}{|l|}{$\operatorname{BMI}^{5}\left(\mathrm{~kg} / \mathrm{m}^{2}\right)$} \\
\hline $18.5-24.9$ & 13 & -7.7 & 3.4 & -5.7 & 3.5 & 4 & -6.8 & 5.0 & -5.7 & 5.0 \\
\hline $25.0-29.9$ & 17 & -6.6 & 2.5 & -4.5 & 2.5 & 19 & -4.7 & 3.0 & -3.6 & 3.1 \\
\hline $30.0-34.9$ & 5 & -1.4 & 2.3 & 0.9 & 2.3 & 2 & -2.2 & 2.9 & -0.9 & 3.0 \\
\hline
\end{tabular}

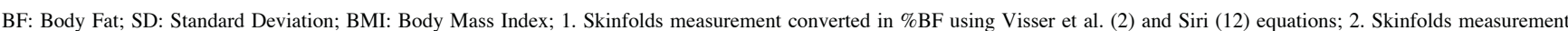

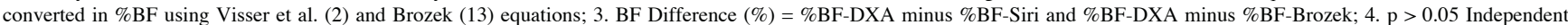
Samples $t$ test for BF Difference $(\%)$ for both genders; 5 . One Way Anova test for BF Difference $(\%)$ for women $(\mathrm{p}<0.05)$ and for men $(\mathrm{p}>0.05)$. 


\section{ACCURACY OF SIRI AND BROZEK EQUATIONS IN THE PERCENT BODY FAT ESTIMATION IN OLDER ADULTS}

and despite the high limits of agreement for both pairs, the $\%$ BF-Brozek reflects a better agreement than the \%BF-Siri.

\section{Discussion}

The goal of the present study was to determine which equation Siri or Brozek, provides a more accurate conversion of $\mathrm{BD}$ in \% BF in older people, using DXA as the standard method.

The correlation found between the \%BF assessed by DXA and calculated from ST and the prediction equations was within the range described in the literature for the correlation between ST and \%BF $(r=0.7-0.9)$ (14). Despite the strong correlation found, our results shown that \%BF-Siri and \%BF-Brozek overestimated \%BF-DXA in older adults. However, our differences were smaller than those previously reported by Bemben et al. (15) who found a discrepancy between underwater weighing and anthropometric measures of 7.5 to $9.5 \%$ in a group of 40 elderly subjects aged $60-74$ years. On the other hand, Kensara et al. concluded that the \%BF estimated from ST was not significantly different from DXA evaluation (28) in a sample of 32 men aged 64-72 years.

Despite the significant differences, our results showed that the \%BF-Brozek provides a better approximation to \%BF-DXA compared to \%BF-Siri approach. The results are also confirmed by the Bland and Altman plots. In fact, \%BF-Brozek provides an improvement of $1.7 \%$ (SD: $0.5 \%$ ) in the accuracy of BD conversion in $\% \mathrm{BF}$ for the overall sample. Moreover, our data demonstrated that this improvement in \%BF estimation was higher for women, $2.1 \%$ (SD: $0.2 \%$ ) than for men, $1.1 \%$ (SD: $0.1 \%$ ). Accordingly, the suggestion of a bias in the prediction of density that leads to a systematic error in the estimation of body fat in older subjects is more likely to have practical significance in women than men (29). In fact, the fat-free mass chemical composition changes with age in females, due to the loss of minerals is considerably higher than the decrease in protein and water (17) and those considerations are supported by our results.

Considering our significant differences between $\% \mathrm{BF}$ evaluated by DXA and calculated from ST and body composition prediction equations it is likely that the observed differences might result, at least partially, from the use of the Visser et al. equation to calculate BD (2). Nevertheless, the differences between underwater weighing, used to obtain the Siri and Brozek equations, and DXA, the reference method that operates with the three compartment model, are the strongest concurrent underlying reasons for our findings.

Finally and central to the considerations of this discussion many influences might be considered, as for example: the aging process, namely the chemical composition changes, such as total body water; shifts in intracellular and extracellular water; the proportion of potassium in lean tissue and the decreases in the mineral content (15), which affect the assumptions of the two compartment model. In the \%BF determination from ST, it is assumed that there is a fixed relationship between subcutaneous adipose tissue and deep adipose tissue (14). However, age differences have already been observed in the relations between subcutaneous adipose tissue and deep adipose tissue (30), as older individuals have relatively more fat accumulated internally (31).

The significant differences found in \%BF estimates between the DXA and the prediction equations used may question the accuracy of both Siri and Brozek equations on conversion of $\mathrm{BD}$ to $\% \mathrm{BF}$ estimation in older people. However, the lack of studies concerning the body composition evaluation in older adults from ST measurement does not allow us to reach a conclusion in regards to this issue. Given that the ST technique is a relevant method to estimate body fat of older people (4) and is dependent on equations to transform $\mathrm{BD}$ to $\% \mathrm{BF}$, its study is of great importance.

Our sample was composed of well-functioning communitydwelling individuals and is not representative of all older adults. So, care should be taken in extrapolating those results to very old and weak individuals, or less physically active populations, and to subjects with significantly different $\% \mathrm{BF}$ and ages.

In summary, the results of the present study show that the use of Brozek equation may correspond to a better alternative than Siri equation for the conversion of BD in \%BF from ST measurement in older adults.

Acknowledgment: Marques E was supported by a doctoral grant from FCT-MCTES (SFRH/BD/36319/2007). Guerra RS was supported by a research grant from FCT-MCTES (POCTI/ISFL/416-10)

Financial disclosure: None of the authors had any financial interest or support for this paper.

\section{References}

1. Deurenberg P, Deurenberg-Yap M. Ageing and changes in body composition: the importance of valid measurements; in: Food for the ageing population. Cambridge, Woodhead Publishing Limited; 2009, Chap 9, pp. 169-183.

2. Visser M, van den Heuvel E, Deurenberg P. Prediction equations for the estimation of body composition in the elderly using anthropometric data. Br J Nutr 1994; 71(6):823-33.

3. Gibson RS. Anthropometric Assessment of Body Composition; in: Principles of Nutritional Assessment. 2nd ed. New York, Oxford University Press; 2005, Chap 11, pp. 272-289.

4. Omran ML, Morley JE. Assessment of protein energy malnutrition in older persons, part I: History, examination, body composition, and screening tools. Nutrition. 2000; 16(1):50-63.

5. Huerta RH, Esparza-Romero J, Urquidez R, Pacheco BI, Valencia ME, AlemánMateo H. Validity of an equation based on anthropometry to estimate body fat in older adults. Arch Latinoam Nutr. 2007; 57(4):357-65.

6. Pongchaiyakul C, Kosulwat V, Rojroongwasinkul N, Charoenkiatkul S, Thepsuthammarat K, Laopaiboon M, Nguyen TV, Rajatanavin R. Prediction of percentage body fat in rural Thai population using simple anthropometric measurements. Obes Res. 2005; 13(4):729-38.

7. Kwok T, Woo J, Lau E. Prediction of body fat by anthropometry in older Chinese people. Obes Res. 2001; 9(2):97-101.

8. Peterson MJ, Czerwinski SA, Siervogel RM. Development and validation of skinfold-thickness prediction equations with a 4-compartment model. Am J Clin Nutr. 2003; 77(5): 1186-91.

9. Ball SD, Altena TS, Swan PD. Comparison of anthropometry to DXA: a new prediction equation for men. Eur J Clin Nutr. 2004; 58(11): 1525-31.

10. Ball SD, Swan PD, DeSimone R. Comparison of anthropometry to dual energy X-ray absorptiometry: a new prediction equation for women. Res Q Exerc Sport. 2004 75(3): $248-58$ 


\section{THE JOURNAL OF NUTRITION, HEALTH \& AGINGC}

11. van der Ploeg GE, Gunn SM, Withers RT, Modra AC. Use of anthropometric variables to predict relative body fat determined by a four-compartment body composition model. Eur J Clin Nutr. 2003; 57(8):1009-16.

12. Siri WE. Body composition from fluid spaces and density: analyses of methods; in: Techniques for measuring body composition. Washington DC, Natl Acad. Sci National Res. Council, 1961, pp. 223-244.

13. Brozek J, Grande F, Anderson T, Keys A. Densitometric analysis of body composition: Revision of some quantitative assumptions. Ann N Y Acad Sci 1963; 26(110):113-40.

14. Heymsfield SB, Lohman TG, Wong Z, Going SB. Human Body Composition, 2nd edition. Champaign, IL: Human Kinetics; 2005.

15. Bemben MG, Massey BH, Bemben DA, Boileau RA, Misner JE. Age-related variability in body composition methods for assessment of percent fat and fat-free mass in men aged 20-74 years. Age Ageing 1998; 27(2):147-53.

16. Goran MI, Toth MJ, Poehlman ET. Assessment of research-based body composition techniques in healthy elderly men and women using the 4 compartment model as a criterion method. Int J Obes Metab Disord 1998; 22(2):135-42.

17. Deurenberg P, Weststrate JA, van der Kooy K. Is an adaptation of Siri's formula for the calculation of body fat percentage from body density in the elderly necessary? Eur J Clin Nutr 1989; 43(8):559-67.

18. Arroyo M, Rocandio AM, Ansotegui L, Herrera H, Salces I, Rebato E. Comparison of predicted body fat percentage from anthropometric methods and from impedance in university students. Br J Nutr. 2004; 92(5):827-32.

19. Yao M, Roberts SB, Ma G, Pan H, McCrory MA. Field methods for body composition assessment are valid in healthy chinese adults. J Nutr. 2002; 132(2):310 7.

20. Haapala I, Hirvonen A, Niskanen L, Uusitupa M, Kröger H, Alhava E, Nissinen A. Anthropometry, bioelectrical impedance and dual-energy X-ray absorptiometry in the assessment of body composition in elderly Finnish women. Clin Physiol Funct Imaging 2002; 22(6):383-91.

21. Svendsen OL, Haarbo J, Heitmann BL, Gotfredsen A, Christiansen C. Measurement of body fat in elderly subjects by dual-energy x-ray absorptiometry, bioelectrical impedance, and anthropometry. Am J Clin Nutr 1991; 53(5):1117-23.
22. Salamone LM, Fuerst T, Visser M, Kern M, Lang T, Dockrell M, Cauley JA, Nevitt M, Tylavsky F, Lohman TG. Measurement of fat mass using DEXA. a validation study in elderly adults. J Appl Physiol 2000; 89(1):345-52.

23. The World Medical Association, Declaration of Helsinki [homepage]. WMA; 2008 [quoted on 2009 Dec 04]. Policy. Available in: http://www.wma.net/en/30 publications/10policies/b3/index.html

24. Marfell-Jones M, Olds T, Stewart A, Carter L. International standards for anthropometric assessment. South Africa, Potchefstroom, International Standards for Anthropometric Assessment, 2006.

25. Coin A, Sergi G, Minicuci N, Giannini S, Barbiero E, Manzato E, Pedrazzoni M, Minisola S, Rossini M, Del Puente A, Zamboni M, Inelmen EM, Enzi G. Fat-free mass and fat mass reference values by dual-energy X-ray absorptiometry (DEXA) in a 20-80 year-old Italian population. Clin Nutr 2008; 27(1):87-94.

26. WHO, 2000. Obesity: preventing and managing the global epidemic. Report of a WHO Consultation. WHO Technical Report Series 894. World Health Organization, Geneva.

27. Bland JM, Altman DG. Statistical methods for assessing agreement between two methods of clinical measurement. Lancet 1986; 1(8476):307-10.

28. Kensara OA, Wootton SA, Phillips DI, Patel M, Jackson AA, Elia M. Fetal programming of body composition: relation between birth weight and body composition measured with dual-energy X-ray absorptiometry and anthropometric methods in older Englishmen. Am J Clin Nutr 2005; 82(5):980-7.

29. Reilly JJ, Murray LA, Wilson J, Durnin JV. Prediction of body density from skinfold thickness in elderly subjects: are the existing equations valid? Ann Hum Biol 1994; 21(6):613-6.

30. Durnin JVGA, Womersley J. Body fat assessed from total body-density and its estimation from skinfold thickness: measurements on 481 men and woman aged from 16 to 72 years. Br J Nutr. 1974; 32(1): 77-97.

31. Schwartz RS, Shuman WP, Bradbury VL, Cain KC, Fellingham GW, Beard JC, Kahn SE, Stratton JR, Cerqueira MD, Abrass IB. Body fat distribution in healthy young and older men. J Gerontol. 1990;45(6):181-5. 